\title{
Case of a Vanishing Colonic Mass
}

\author{
Lisa Barrett, DO ${ }^{1}$, Abhinav Goyal, MD², Nathan Davis, DO², Yogesh Govil, MD², and Stacey Zavala, MD² \\ ${ }^{1}$ Department of Internal Medicine, Einstein Medical Center, Philadelphia, PA \\ ${ }^{2}$ Department of Gastroenterology, Einstein Medical Center, Philadelphia, PA
}

\section{ABSTRACT}

Colonic ischemia most often presents with abdominal pain and rectal bleeding. Presentation of colonic ischemia as a prominent mass is exceptionally unique and is not often reported. Concern for neoplasm prompted a repeat scope, which revealed the mass had vanished. We present a case of colonic ischemia, which produced a transient colonic mass formed by inflammatory tissue and clots.

\section{CASE REPORT}

A 58-year-old woman with a medical history of multiple sclerosis complicated by ventilator-dependent chronic respiratory failure, status post tracheostomy, and gastrostomy tube presented to the emergency department with 1 day of maroon stool. At presentation, she was afebrile and hemodynamically stable. On physical examination, her abdomen was slightly distended, nontender, and nontense with an unremarkable percutaneous endoscopic gastrostomy site. The digital rectal examination was positive for maroon stool. Laboratory tests revealed a white blood cell count of $9.5 \times 10^{3} / \mathrm{mcL}$, hemoglobin $10.1 \mathrm{~g} / \mathrm{dL}$, blood urea nitrogen $14 \mathrm{mg} / \mathrm{dL}$, creatinine $0.3 \mathrm{mg} / \mathrm{dL}$, and lactic acid $0.87 \mathrm{mmol} / \mathrm{L}$. Abdominal computed tomography with contrast showed distal colonic distension measuring $7.9 \mathrm{~cm}$ in its largest dimension, a large stool burden resulting in fecal impaction throughout the distal colon, and an area of focal narrowing in the sigmoid colon.

The patient was admitted and prepared for colonoscopy. She continued to have maroon stools with a drop in hemoglobin from 11.1 to $9.1 \mathrm{~g} / \mathrm{dL}$. On colonoscopy, findings included a $6-\mathrm{cm}$ ulcerated, friable, partially obstructing mass in the descending which

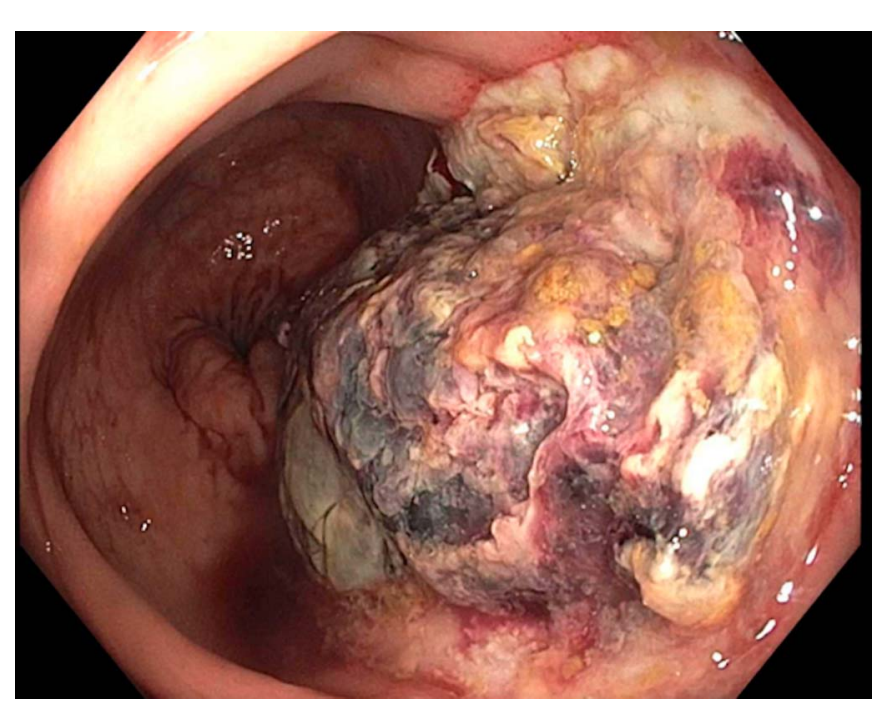

Figure 1. Mass noted during initial colonoscopy.

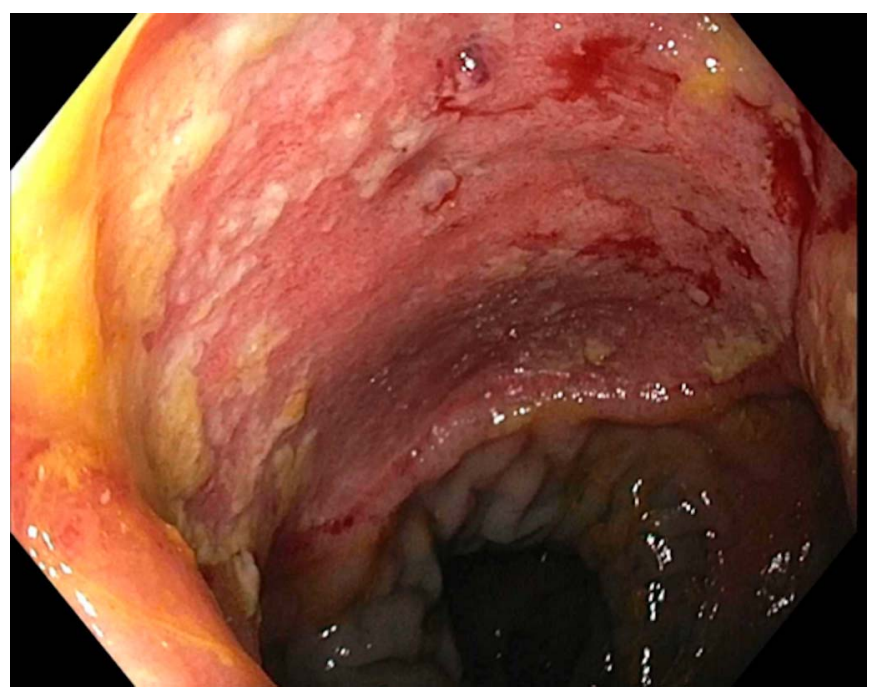

Figure 2. Ulcerated lesion instead of previously noted mass during repeat flexible sigmoidoscopy. 
was biopsied (Figure 1). The proximal and distal regions of the lesion were then tattooed using carbon black. Pathology demonstrated fragments of acute inflammatory cellular debris, fibrin, and blood. Given the inconclusive biopsy result, flexible sigmoidoscopy was performed 2 days later. On inspection of the tattooed region, no mass was visualized. Instead, an ulcerated lesion with granular, erythematous mucosa was found (Figure 2). Multiple biopsies were performed at the edges and center of this lesion. Histology revealed ulcerated colonic mucosa, granulomatous tissue, fibrin, and acute inflammatory cellular debris concerning for ischemia.

Ischemic colitis can present in a variety of ways. However, presentation as a protuberant mass in the distal colon is rare and has only been reported in a few cases. ${ }^{1,2}$ Our patient was noted to have a mass on initial colonoscopy which was believed to be a neoplastic lesion. The biopsy result demonstrated findings of inflammatory debris which was believed to be nondiagnostic at the time, however, likely represented colonic ischemia. The mass was a result of organized debris and clots resulting from tissue ischemia. This case, therefore, provides an essential entity for the differential diagnosis of colon mass, especially when biopsy results are nondiagnostic and nonspecific.

\section{DISCLOSURES}

Author contributions: L. Barrett and N. Davis wrote the manuscript. A. Goyal, Y. Govil, and S. Zavala edited the manuscript. L. Barrett is the article guarantor.

Financial disclosure: None to report.

Informed consent was obtained for this case report

Previous presentation: This case was presented at the American College of Gastroenterology Annual Scientific Meeting; October 25-30, 2019; San Antonio, Texas.

Received November 9, 2020; Accepted May 7, 2021

\section{REFERENCES}

1. Brandt LJ, Katz HJ, Wolf E1, Mitsudo S, Boley SJ. Simulation of colonic carcinoma by ischemia. Gastroenterology. 1985;88(5 pt 1):1137-42.

2. Deepak P, Devi R. Ischemic colitis masquerading as colonic tumor: Case report with review of literature. World J Gastroenterol. 2011;17(48):5324-6.

Copyright: ( 2021 The Author(s). Published by Wolters Kluwer Health, Inc. on behalf of The American College of Gastroenterology. This is an open access article distributed under the terms of the Creative Commons Attribution-Non Commercial-No Derivatives License 4.0 (CCBY-NC-ND), where it is permissible to download and share the work provided it is properly cited. The work cannot be changed in any way or used commercially without permission from the journal. 